\title{
GUERRA EN EL PARAÍSO DE CARLOS MONTEMAYOR: REPRESENTACIÓN DEL MONSTRUOSO ESTADO MEXICANO
}

Guadalupe Pérez-Anzaldo

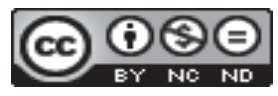

Esta obra está bajo una licencia Creative Commons 



\title{
GUERRA EN EL PARAÍSO DE CARLOS MONTEMAYOR: REPRESENTACIÓN DEL MONSTRUOSO ESTADO MEXICANO

\author{
GUERRA EN EL PARAÍSO BY CARLOS MONTEMAYOR:
} REPRESENTATION OF THE MONTRUOUS MEXICAN STATE
}

\author{
Guadalupe Pérez-Anzaldo
}

\begin{abstract}
RESUMEN
La novela de Carlos Montemayor, Guerra en el paraíso, es analizada a partir de la simbología que en ella persiste en relación a la monstruosidad del Estado mexicano. De acuerdo con la conceptualización hecha por Tomás Hobbes, el Estado es como un Leviatán o monstruo gigante a quien los ciudadanos le confieren el poder absoluto buscando ser protegidos de las agresiones de los demás. En la emisión representacional de la novela de Montemayor, el Estado mexicano es un engendro capaz de cometer sagazmente distintas masacres, como las perpetradas durante los años de la Guerra Sucia, sin que hasta ahora haya sido posible contenerlo. La violencia legitimada y desplegada durante esos años aciagos en contra de los guerrilleros encabezados por Lucio Cabañas es expuesta en este texto literario con el propósito de insertar ese pasado obliterado en el discurso historiográfico. En contraste con la bestia despiadada representada por el Estado mexicano, a los guerrilleros se les asocia con la naturaleza, misma que es personificada para resaltar el dolor provocado por la hecatombe dirigida por el régimen estadounidense. Con esta novela, Montemayor refuerza su compromiso social de denunciar la violencia que ha prevalecido en el país para mantener sometida a la población.
\end{abstract}

Palabras clave: monstruo, Estado, Leviatán, guerra, paraíso.

\begin{abstract}
Carlos Montemayor's novel, Guerra en el paraíso, is analyzed based on the predominant symbolism related to the monstrosity that characterizes the Mexican State. According to the conceptualization made by Thomas Hobbes, the State is similar to a Leviathan, a giant monster to whom all citizens concede absolute power to in an effort to be protected from the aggressions of others. Within the symbolic emission of this novel by Montemayor, the Mexican State is a savage entity that secretly commits diverse massacres, in similar fashion to crimes executed during the years of the Dirty War, without being stopped. The legitimized violence exhibited during those dark years against the guerilla members headed by Lucio Cabañas is exposed in this literary narrative with the objective to bring to light those obliterated events in the historiography discourse. In contrast to the cruel fiend represented by the Mexican State, guerrilla members are associated with nature, which is personified to emphasize the pain endured by the people as consequence to the destruction ordered by the American government. Throughout his novel, Montemayor empathizes his social commitment to denounce the prevalent violence in Mexico used to control its people.
\end{abstract}

Key words: monster, State, Leviathan, war, paradise.

Dra. Guadalupe Pérez-Anzaldo. Universidad de Missouri-Columbia. Assistant Profesor of Spanish Department of Romance Languages \& Literatures. Estados Unidos.

Correo electrónico: perezgu@missouri.edu

Recepción: 06- 04- 2015

Aceptación: 19- 06- 2015 
El término legitimidad no es justo. Pensamos que cuando un grupo toma las armas la violencia se desata. Se nos olvida que hay una violencia anterior, una violencia que se ejerce de manera despiadada; es la violencia del hambre, la violencia del despojo, la violencia de la represión y la explotación, la violencia de la falta absoluta de justicia, la violencia de la corrupción, la violencia de los asesinatos y las desapariciones políticas.

Carlos Montemayor (Vázquez-Martín, 1997, párr. 8)

Cuando en Latinoamérica se estudia el devenir de la violencia en las últimas cuatro décadas del siglo XX, por lo general se toman como punto de referencia las guerras sucias llevadas a cabo en los países de centro y Sudamérica. Sin embargo, aquella ocurrida en México (desde finales de los años 60 hasta principios de la década de los 80), ha sido borrada de la narrativa oficial. De ahí que pueda afirmarse que la estrategia de silenciamiento en torno a las brutalidades perpetradas por el Estado mexicano en contra de sus vulnerables ciudadanos ha sido efectiva a nivel global. Escasos han sido los escritores que se han propuesto exhibir la violencia física y estructural desplegada por las élites gobernantes en México para someter a los grupos subordinados que desafían la normatividad que les es impuesta. En particular, Carlos Montemayor resulta un caso emblemático porque en su novela Guerra en el paraíso (1991), ha proyectado un México caótico donde la monstruosidad practicada por el Estado tiene el papel protagónico. En dicho texto testimonial-histórico-político, Montemayor (re)crea la cacería oficial desplegada en el estado de Guerrero - la cual dejó a su paso miles de muertos y destrucción ecológica- para eliminar a la guerrilla encabezada por el maestro rural Lucio Cabañas.

Este escritor mexicano elabora una re-visión de la noción de historia al rememorar un pasado obliterado por el discurso oficial con la finalidad de reinsertarlo en la memoria colectiva, mediante una narración fragmentada donde figuran los nombres verdaderos de las figuras históricas involucradas en estos hechos sangrientos. El compromiso social de Montemayor, por lo tanto, es evidente en la re-construcción de aquellos hechos históricos incómodos para las élites políticas binacionales en su novela; algo que es muy difícil de lograr cuando no se tiene acceso a archivo alguno, tal y como el mismo escritor lo confirma en la siguiente cita:

\footnotetext{
Comencé una investigación que duraría cinco años, misma que incluía la consulta de material bibliográfico muy escaso, así como la entrevista a un grupo de sobrevivientes. Mi investigación fue muy ardua y entrevisté a tanta gente para Guerra en el paraíso que, cuando la gente me asegura que ésta es una novela histórica, no puedo menos que aceptarlo, pero con la advertencia de que una novela histórica tradicional se fundamenta en datos históricos documentados. En este caso, no existe tal información documentada. ${ }^{1}$ (Long, 2006, p. 39)
}

De ahí que pueda afirmarse que el texto de Montemayor resulta ser muy complejo en tanto que en él se conjugan discursos oficiales, conferencias de prensa, reportes periodísticos; al tiempo que se re-crean conversaciones telefónicas e interpersonales, así como monólogos interiores del protagonista (Lucio Cabañas) y otros personajes. Dicha mezcla de ficción, testimonio, política e historia le permite al escritor mexicano presentar una visión más amplia del genocidio ocurrido en Guerrero durante la guerra sucia y dotar nuevamente de su calidad humana a los guerrilleros que se vieron orillados a tomar las armas. Esto último en contraste con la caracterización monstruosa que se hace de las fuerzas armadas y los políticos mexicanos y extranjeros.

Un texto teórico clave para analizar de qué manera se representa la monstruosidad del Estado mexicano en Guerra en el paraíso, lo constituye Leviatán (1651) de Tomás Hobbes; especialmente porque en éste se propone la formación de un Estado (o civitas en latín) capaz de ejercer el poder político absoluto con el fin de resguardar el bien común a costa del 
sometimiento de todos sus gobernados, siempre proclives a actuar irracionalmente debido a sus pasiones naturales. Lo más significativo de la teoría política de este filósofo inglés es que se conceptualiza al Estado -constituido de una persona artificial o un determinado grupo de hombres- a partir de la bestia bíblica Leviatán:

\begin{abstract}
[A]quel dios mortal, al cual debemos, bajo el Dios inmortal, nuestra paz y nuestra defensa. Porque en virtud de esa autoridad que se le confiere por cada hombre particular en el Estado, posee y utiliza tanto poder y fortaleza, que por el terror que inspira es capaz de conformar las voluntades de todos ellos para la paz, en su propio país, y para la mutua ayuda contra sus enemigos, en el extranjero. [cursiva agregada] (Hobbes, s.f., p. 72.)
\end{abstract}

Es decir, el Estado es para Hobbes un dios, un engendro gigante y espantoso a quien le es conferida, por medio de las leyes, la obediencia incondicional de los hombres. En ese sentido, la voluntad del ser humano es controlada no sólo por su deseo de ser protegido de las agresiones desbordadas de los otros individuos (razón principal que el pensador inglés identifica para la creación del Estado), sino a su inmenso temor de ser castigado por dicho monstruo. Cabe enfatizar que lo que Hobbes no vislumbró en su texto escrito hace más de 360 años, sin embargo, fue la vulnerabilidad del ciudadano común, o su falta de protección, ante tanto poder acumulado por la élite política; puesto que al ser el Estado una entidad abstracta, también está propensa a utilizar la violencia para satisfacer sus "pasiones naturales", en este caso, su ambición desmedida por conservar la cohesión social que a su vez le permita refrendar su poder. Hobbes tampoco consideró que los grupos hegemónicos dejarían de operar bajo los límites temporales y espaciales de las naciones-estados; sino que sus funciones, tanto políticas como económicas, llegarían a descentralizarse y multidimensionarse a escala mundial.

Esa es justo la problemática que se expone en la novela Guerra en el paraíso mediante la simbolización del Estado mexicano como una máquina o monstruo sanguinario que, como el dios mítico romano Saturno, devora a sus hijos para evitar que su autoridad sea confrontada y anulada. Peor aún, ese dios ni siquiera actúa con autonomía ni voluntad propias, sino que obedece los designios de un ente mucho más poderoso y bestial (Estados Unidos) que, acechando desde la penumbra, mueve sus múltiples brazos para colocar en sitios estratégicos las piezas individuales que más se amolden al complejo entramado que lo sustenta y fortalece. El sacrificio de la sangre inocente, por lo tanto, es indispensable para que este inmenso monstruo que opera a nivel mundial se mantenga con vida.

Para contextualizar la idea anterior, es importante resaltar que la Guerra Sucia en México se perpetró en el contexto de la disputa beligerante entre las dos principales potencias mundiales, Estados Unidos y la Unión Soviética, por conseguir y mantener la hegemonía mundial y global: la llamada Guerra Fría. En particular, Estados Unidos implementó la fundación de la Escuela de las Américas en Panamá, en 1946, con el objetivo primordial de entrenar en tácticas militares y de contrainsurgencia a miles de soldados pertenecientes a diversos países latinoamericanos que ayudarían a contener los avances comunistas en este continente (Gill, 2004, p. 6). De ahí que la trayectoria tomada por Cuba después del triunfo de la Revolución Cubana iniciada en 1959, significó una amenaza para la supremacía estadounidense; nación que buscó evitar por todos los medios que en Latinoamérica surgiera otro país que emulara los pasos de dicha isla caribeña. Por lo consiguiente, la aparición de grupos guerrilleros en México encendió nuevamente las señales de alarma y fue así como se dio inicio a la violencia consumada de forma directa por el Estado mexicano -apoyado económica, técnica y estratégicamente por el norteamericano, según se denuncia en la novela de Montemayor- para reprimir y exterminar a todo agente 
considerado subversivo o "comunista" que pudiera poner en riesgo la estabilidad política y financiera de la potencia estadounidense.

Las raíces de esta Guerra Sucia implementada en México se remontan a la violencia estructural sufrida por la mayoría de la población mexicana, en particular la guerrerense, a manos de un Estado corrupto y opresor. Eso es justo lo que analiza el mismo Carlos Montemayor en su libro La violencia de Estado, donde hace énfasis en el surgimiento de los movimientos sociales en el siglo XX en México aseverando que la inconformidad social tiene sus orígenes en:

[L]a pobreza, la desnutrición, el desempleo, el analfabetismo, la marginación, la carencia de servicios de salud, la vivienda deficiente, los servicios públicos insuficientes o inexistentes, la desigualdad social extrema, la pérdida de talla o estatura en núcleos rurales e indígenas, el acortamiento del promedio de vida en zonas rurales y marginadas. (Montemayor, 2010, p. 182)

Estas causas serían suficientes para explicar los distintos brotes de descontento hacia sus gobernantes entre la población civil, en especial en las zonas rurales del país, pero la revuelta social que dio origen a la guerra sucia en el estado de Guerrero fue detonada por razones más específicas, la irracionalidad de la oligarquía política que urdió un plan siniestro y genocida para desaparecer literalmente a los grupos inconformes:

\footnotetext{
Fueron policías judiciales de Guerrero, actuando como grupos de choque, los causantes de la masacre en la plaza central de Atoyac el 18 de mayo de 1967. Los padres de familia de la escuela primaria Juan Álvarez se manifestaron para protestar por las elevadas cuotas que la directora de la escuela imponía a los estudiantes. Los policías judiciales acuartelaron a los policías preventivos y atacaron a la población, como describo pormenorizadamente en la novela Guerra en el Paraíso. Las autoridades quisieron culpar a Lucio Cabañas de la masacre e intentaron aprehenderlo; ese día Lucio se vio obligado a remontarse a la sierra: así se originó la guerrilla. (Montemayor, 2010, p. 191)
}

Efectivamente, los efectos nocivos de este conflicto armado son estéticamente re-creados por Montemayor en Guerra en el paraíso donde predomina una narración fragmentada y polifónica que se alterna entre la tercera persona y el monólogo interior. Aunque hay un énfasis en las actividades realizadas por la guerrilla encabezada por Lucio Cabañas -desde el surgimiento de ésta a partir de 1967, con la subsecuente formación de El Partido de los Pobres, hasta la muerte del líder guerrillero en 1974- también hay referencias al asesinato perpetrado por militares en 1972 de otro maestro rural forzado a convertirse en guerrillero, Genaro Vázquez Rojas. Inclusive, la historia ficcionalizada se remonta a 1963, cuando Lucio Cabañas todavía trabajaba como maestro rural; ello no sólo para profundizar en las causas que lo orillaron a convertirse en guerrillero, sino para reforzar su personalidad pacifista y altruista.

Desde el comienzo de la narración cargada de un lenguaje poético, se establece una conexión entre el dolor físico, el sufrimiento anímico, la deshumanización de los grupos insurgentes, la agonía y la subsecuente muerte violenta de la empobrecida sociedad civil con la deforestación, la contaminación del agua y aire, la violación y exterminio de animales y la devastación en general que toda guerra conlleva. Según lo expuesto en la novela de Montemayor, el Leviatán mexicano aprovecha que los grupos insurgentes se encuentran asentados en las montañas de Guerrero, donde la infraestructura es casi inexistente, para utilizar diferentes estrategias que le ayuden a restablecer el Orden tan anhelado por los grupos hegemónicos: sólo construye caminos que le ayuden a los soldados a acceder a los asentamientos guerrilleros, quema poblados enteros, tortura y desaparece hombres, mujeres y niños por igual, niega la existencia de guerrilleros y elabora mentiras difundidas 
mediáticamente para encubrir los acontecimientos reales, utiliza a doctores como espías y asistentes en la tortura que cotidianamente practica, usa las estadísticas recabadas en el censo para controlar a la población, utiliza la asistencia social (como la CONASUPO, Compañía Nacional de Subsistencias Populares) para racionalizar el abasto de alimentos, amenaza y reprime a los periodistas, utiliza al Ministerio Público para aplicar las leyes a conveniencia entre muchas otras prácticas de violencia física y estructural.

El brazo ejecutor de las maquinaciones hechas por la oligarquía política lo constituyen las fuerzas castrenses mexicanas; mismas que practican impunemente los actos más salvajes y depravados de forma institucionalizada. Es en Guerrero donde "[E]l Estado le dio a su Ejército vía libre para cometer toda clase de excesos, y con la asistencia de altos mandos de corporaciones policíacas se llevaron a cabo detenciones arbitrarias, torturas, ejecuciones extrajudiciales y desapariciones forzadas" (Oikión-Solano, 2007, p. 67). Eso es precisamente lo que se evidencia en Guerra en el paraíso donde dichos actos despiadados son descritos por el protagonista Lucio Cabañas con lujo de detalles:

\footnotetext{
A los campesinos que detiene el ejército los están matando [...] Los golpean, los torturan. Luego los suben en helicópteros y los arrojan vivos al mar, o a los cerros, o los entierran vivos [...] Y en el cuartel de Atoyac abren zanjas y ahí acuestan a muchos, vivos, atados de las manos, y luego les echan tierra con máquinas y emparejan el piso, para que no se note que todos los que ustedes llaman detenidos los mata el ejército asesino de Cuenca Díaz que usted tanto defiende. Y en otros lugares los meten en sacos y les echan calidra, mientras están vivos, hasta que mueren (Montemayor, 2013, p. 372)
}

Por lo tanto, en el imaginario simbólico de la novela, al Ejército se le asocia con una fuerza maligna, una bestia feroz que propaga el terror profanando la naturaleza y exterminando la vida humana; eso es justo lo que se aprecia en distintas citas textuales de la novela, entre las que se encuentran las siguientes: "El ejército era rotundo, inmenso, parecía una ola verde y oscura que cubriera la tierra, los escombros. Cautivaba como una súbita hierba hermosa, ágil, brutal" (Montemayor, 2013, p. 151); "El ejército siempre hará esas cosas. Saquear, violar mujeres, matar ancianos, niños, a todos [...] el ejército recorre todos los ejidos y secuestra, y mata, y tortura" (2013, p. 316); "El ejército vigila pueblos enteros. Mata niños, viejos, mujeres” (2013, p. 346); "el ejército sigue en la sierra, aquí mismo, no ha disminuido, pues. Mata, tortura, apresa, destruye casas, destruye pueblos enteros" (2013, p. 415). La presencia de las fuerzas armadas, por consiguiente, únicamente ha servido para eliminar la paz e inocencia del paraíso en la tierra; cabe advertir que el Paraíso también se refiere a un poblado ubicado en el feraz estado de Guerrero.

No por casualidad, un misionero que es apresado por los soldados les grita angustiado: “-¡Ustedes son el vivo Satanás!” (2013, p. 422); puesto que de esta forma, la institución militar es deslegitimada y desacralizada al asociársele con la maldad suprema, el monstruo despiadado que corrompe almas y destruye la vida a su paso. En especial, llama la atención la degeneración moral en la que sucumben los militares cuando violan sin misericordia a una becerrita frente a los horrorizados ojos de un campesino, lo que refuerza su condición de bestias crueles ante el sufrimiento de los seres humanos y de los animales:

\footnotetext{
Eran más de diez soldados, todos jóvenes. Una becerrita mugía bajo el peso con que la doblegaba el grupo. Varios de ellos estaban sin camisa. Dos de los soldados estaban sin pantalones. El soldado que estaba sujetando la cabeza oscura de la becerra gritó a los demás, como si los gritos se confundieran con la risa [...] En uno de los soldados sin pantalones alcanzó a distinguir, como un pequeño muñón oscuro, una pequeña rama oscura, el miembro erecto que se agitaba con los pasos y con el esfuerzo por sujetar parte del cuerpo de la becerra. Vio que el otro soldado sin pantalones metía ya el miembro oscuro en la hendidura rosada de la becerrita, tensas las piernas, levantados ligeramente los talones, apretadas y moviéndose nerviosamente las nalgas, extendidos los brazos sobre el cuerpo del animal que mugía. (Montemayor, 2013, p. 477)
} 
La irracionalidad generada y exacerbada por el Estado mexicano en detrimento tanto de los guerrilleros como de los campesinos y gente pobre que apoya las acciones de ese grupo sublevado, no termina sino hasta hacerles perder su condición humana porque, como lo asegurara la filósofa francesa Simone Weil: "la violencia convierte en cosa a quien está sujeto a ella" (Citada por Sontag, 2004, p. 21). Eso es justo lo que se proponen las élites dominantes cuando exhiben todo su poderío militar en aras de atemorizar, controlar y exterminar a sus frágiles víctimas, quienes en la mayoría de los casos descritos en la novela terminan como simples despojos por el delito de ser pobres, por no hablar el español, por indagar sobre sus familiares desaparecidos, por ser acusados de ayudar a los grupos insurgentes, por no delatarlos, etc. Con saña, los soldados torturan a los campesinos y ya dentro de los helicópteros "los oyen gemir roncamente como animales [antes de lanzarlos] al vacío, sobre el mar, sobre la sierra, atravesando como una lluvia de vida desgarrada, la lluvia de crueldad de los ejércitos" (Montemayor, 2013, p. 561). En ese sentido, el sistemático terrorismo perpetrado por el Estado en contra de la población civil expone la vulnerabilidad de esta última a la que se supone debería de proteger, por lo que:

\footnotetext{
De todas las formas imaginables de terror, el de Estado es, por su carácter perverso, el peor de todos. El sentimiento de indefensión es tanto mayor cuanto que el Estado se conforma teóricamente para la defensa de los intereses del colectivo en el que se inserta el individuo. Por eso resulta tan difícil hacerle frente y por eso, ante la agresión que viene de arriba, la única defensa posible es la huida, el exilio, con la consiguiente pérdida. Así el Estado alcanza igualmente su objetivo, hacer desaparecer del mapa al ciudadano en cuestión. (Pérez-Jiménez, 2007, pp. 171-172)
}

En el caso particular de México, es importante subrayar que aunque éste sea reiteradamente denominado como un país democrático a nivel discursivo, en la práctica demuestra seguir los lineamientos de un régimen dictatorial sustentado en una variedad de mecanismos institucionalizados de represión y control social. El Estado se erige así en guardián del estatus quo que debe ser resguardado a pesar de ir en contra de los intereses de la mayoría de la población, por lo que

\footnotetext{
el orden social establecido se presenta a sí mismo como una defensa en contra de la violencia que estallaría si no estuviese controlada, como en la teoría del contrato social donde una sociedad politizada encuentra su origen y continua justificación ante la latente amenaza de una guerra ${ }^{2}$ (Bernasconi, 2004, p. 84)
}

Esa idea la explora Carlos Montemayor en su novela a través de una conversación sostenida entre los miembros de la cúpula militar, quienes reconocen su participación activa en el reforzamiento del sistema de dominación que ha permitido mantener sometido al Otro marginal: "La función primordial del ejército es fortalecer la seguridad de un país, digamos. Y esa seguridad se busca aun al precio de la guerra. Pero a veces buscando esa paz podríamos sofocar al pueblo mismo, conseguirla al precio de luchar contra el pueblo mismo" (Montemayor, 2013, p. 530).

Significativamente, son los altos mandos militares mexicanos, los que al discutir sobre su papel como protectores del orden establecido advierten del peligro que representa el estar sujetos a los lineamientos emitidos e impuestos por el gobierno de su poderoso vecino del norte. Son también ellos quienes critican la hipocresía de los políticos estadounidenses que promueven la pobreza de millones de mexicanos - lo que a su vez conlleva a la desestabilización de la paz social en el territorio nacional- al mismo tiempo que le ordenan a sus grupos de élite entrenar a las fuerzas armadas mexicanas con el fin de someter y exterminar a los grupos sublevados: 
[E]stamos controlando pueblos enteros, municipios, ciudades, montañas, comunicaciones, todo. Por eso puede caber la duda de si estamos sofocando y luchando contra el pueblo mismo o sólo, como le gusta decir al presidente de la República, contra problemas provocados en México por la CIA [...] Por un lado, Estados Unidos provoca con la CIA este problema en México; por otra, el ejército norteamericano ayuda al ejército mexicano a luchar contra ese problema. (Montemayor, 2013, p. 533)

Así, con las aseveraciones anteriores se reformulan críticamente los postulados teóricos de Hobbes en Leviatán, en tanto que en el caso particular de México el Estado no ha sido constituido para defender a los ciudadanos, ni siquiera para resguardar las fronteras que le impidan a los grupos dominantes extranjeros que tengan/mantengan injerencia en la toma de decisiones que afectan directamente a la población. La violencia normativa que se propaga desde las mismas instituciones encargadas de hacer valer las leyes, por lo tanto, va encausada a desaparecer e invisibilizar a los movimientos sociales (como en el caso de las luchas guerrilleras) en aras del fortalecimiento del sistema capitalista impuesto en el país.

En la conversación de los jefes castrenses mexicanos anteriormente referida, llama la atención que sean ellos quienes se refieran a la CIA como a un monstruo escurridizo y traidor que impone jerarquías de poder en las que el mando supremo lo acapara para sí el hombre blanco:

La CIA es una especie de Medusa que puede tener un tentáculo en Bucareli, otro en Tesorería de la Federación y otro en la esquina más próxima. El ejército, en cambio, nos envía de asesores a los puertorriqueños y envía a Vietnam sus fuerzas chicanas y negras. Ahí cuidan muy bien sus contingentes sajones. (Montemayor, 2013, p. 534)

De este modo, estos beligerantes líderes mexicanos advierten que tanto ellos como las fuerzas armadas que ejecutan el terror legitimado entre la indefensa población civil que habita el país son solamente un instrumento más en el multifacético andamiaje generado y dirigido desde las entrañas del gobierno estadounidense, salvaguarda de los intereses económicos de los grupos hegemónicos que operan a escala global. Son precisamente dichos grupos los que generan la violencia estructural que afecta a millones de individuos a quienes primero se les niegan los servicios más básicos para sobrevivir y después se les criminaliza por exigir sus derechos.

En contraste con la emisión representacional en torno al Estado mexicano como una fuerza remarcablemente destructiva, en Guerra en el paraíso proliferan los signos positivos cuando se alude a la figura de Lucio Cabañas. Este combatiente es descrito no sólo en unión solidaria con la mayoría de la gente de los poblados guerrerenses que recorre con su grupo guerrillero, sino también en relación armoniosa con la naturaleza que le rodea. Es particularmente relevante la identificación de la tierra personificada, en femenino, con Lucio:

[L]a tierra, en lo más secreto de sus entrañas, en lo más profundo de esos montes, de esas verdes profundidades, en El Porvenir, en El Paraíso, en Río Santiago, sentía la misma prisa, se daba cuenta. Y él sabía que era la suya, que era la misma. Que ahí estaba él, donde debía estar. Que ahí estaba la tierra, para que él estuviera ahí. (Montemayor, 2013, pp. 44-45)

Así, Lucio se asemeja a un hijo que ha nacido de las entrañas, de las profundidades de esta tierra, el mismo que sigue sintiendo y respirando al unísono con su madre. El guerrillero es ese vástago que tiene prisa por defender a quien le ha dado la vida y se encuentra en peligro de ser contaminada y "penetrada" por una bestia voraz que, como ya se ha señalado, busca eliminar por completo a todos los que se han levantado en armas y a todos aquellos que los apoyan estratégica, material o moralmente. 
Como a una madre, Lucio respeta a la tierra y valora la protección que ésta le brinda en contra del engendro catastrófico que lo persigue y acorrala, por eso después de haber escupido sin darse cuenta sobre ella "Súbitamente sintió que la ofendía. Que la tierra lo escuchaba y estaba viva, soportándolo, deteniéndolo” (Montemayor, 2013, p. 97). Al igual que él, la tierra tiene una consciencia propia y sabe que el peligro acecha a cada momento, por lo que se mantiene alerta para proteger a su afligido hijo: "Sentía la tierra misma del campamento como si adviertiera de algo, como si pensara ella también” (Montemayor, 2013, p. 423). Como puede apreciarse, cada elemento de la naturaleza ocupa un lugar privilegiado en el imaginario simbólico expuesto a través del protagonista en los azarosos momentos de su persecución; esta subjetividad constituye una fuerza reivindicadora que se encarga de otorgarles cualidades humanas a sus generosos guardianes: "Lucio pensó en ellos como si no se tratra de lugares lejanos, sino de algo íntimo, como una persona. El Cerro del Zanate, el cerro Cabeza de Perro, el del Plan de Molinos, el del Plateado" (Montemayor, 2013, p. 566).

Por otro lado, Lucio y los guerrilleros que lo secundan son capaces de enfrentar los peligros que se ciernen sobre ellos al refugiarse en las montañas, como el hambre y las enfermedades, gracias a su vasto conocimiento de la cartografía de la zona guerrerense. Su resistencia a las condiciones climáticas extremas del lugar, al hambre y a las extenuantes horas de esfuerzo físico mediante las cuales logran mantenerse fuera de la mira del enemigo, los distinguen de sus victimarios: aquellos soldados llegados de otros estados de la República. En particular, los guerrilleros logran subsistir en esas circunstancias adversas ayudados por la naturaleza, la cual se vuelve su aliada incondicional combatiendo con sus propias armas al invasor. Eso es justo lo que descubre un coronel del Ejército después de haber incursionado en las profundidades de las montañas con sus tropas; de ahí que preocupado le advierta a su superior:

[P] ara muchas de nuestras patrullas el enemigo ya no son los rebeldes, sino la sierra misma [...] Muchos se han llagado de las paredes blandas y de las piernas o han regresado palúdicos [...] Muchos están enfermos. Por piquetes de víboras o alacranes, por disentería, por noches y días enteros bajo la lluvia, por llagas en el ano y en los pies (Montemayor, 2013, pp. 442-443)

En particular, la intrínseca interacción entre Lucio y su madre tierra se hace especialmente patente a la hora de su muerte; su sangre se une/confunde con la de esa benevolente tierra que lo hace trascender más allá del espacio físico. A través del lirismo contenido en esta prosa, la muerte del protagonista evoca más bien un renacer, un autodescubrimiento. Es en ese preciso momento que dicho personaje se reconfigura en la semilla que germinará, sobrepasando los avatares de su historia personal, para regenerar en una identidad colectiva en concomitancia con el medio ambiente:

[V]io que las manos de su cuerpo tocaban la roca tratando de apoyarse en ella, y tuvo otra sensación, le pareció entender esa roca, esa tierra del mundo, ese pedazo de sangre blanca, cubierta de tierra, de hojas, blanda y concreta para entender la vida que se acerca a la nuestra, a la de todos los que seguían gritando, de pie, armados, en muchos ejidos, en muchos pueblos, en muchos cuerpos con la espalda rota, con sus huesos estallados (Montemayor, 2013, pp. 582-583)

Puede afirmarse, entonces, que lo que en realidad se promueve en estas líneas citadas arriba es la noción de solidaridad entre las clases marginales, pero también de continuidad del dolor que padecen; en tanto que esta lucha desigual entre quienes acaparan el poder económico y político y aquellos grupos mayoritarios que padecen hambre y sed de justicia no parece tener fin. Paradójicamente, mientras persista la violencia estructural, la cual es denominada por Robert Bernasconi como violencia sistemática, persistirá el uso de la violencia física de parte 
del monstruoso Estado con la cual busque erradicar a todo elemento subversivo. Tiene razón Bernasconi (2004, p. 83) cuando asegura que cada sociedad [o en este caso el Estado] escoge a sus muertos, puesto que aunque haya recursos suficientes para brindarle un buen servicio de salud y alimentar a toda la gente ni siquiera se intenta hacerlo; en la novela de Montemayor, queda muy claro que esos muertos siempre van a ser los ciudadanos más empobrecidos. Lo más grave de todo es que a esos muertos víctimas de la desbordada saña del Estado, se les violenta doblemente al desaparecerlos también a nivel discursivo: no olvidemos que la Guerra Sucia en México continúa siendo casi desconocida no sólo en la narrativa oficial dentro del país, sino también fuera de este.

Como se ha intentado demostrar en este ensayo, Guerra en el paraíso constituye un discurso contestatario que reinserta en la conciencia colectiva eventos sangrientos provocados por el Estado mexicano que han sido erradicados de la historiografía nacional y extranjera. La Guerra Sucia en México es develada de manera desgarradora en esta narración que enfatiza la brutalidad propia del Estado mexicano puesta en práctica para exterminar a poblados enteros en el estado de Guerrero con el propósito principal de proteger los intereses económicos y políticos de la potencia norteamericana. Como se evidencia en la novela de Montemayor, la infiltración del sistema capitalista avasallador no ha conducido al progreso en México, sino a la hecatombe. Ante la persecución y masacre de la gente pobre, solo queda el camino de las armas, pero esa radicalización del Otro marginal no logra la erradicación del régimen monstruoso globalizado que lo mantiene subyugado debido al combate disímil que confronta. Por ello, Carlos Montemayor propone con su narrativa, la concientización de la mayoría de la gente mexicana para que, con base en las enseñanzas de los hechos pasados, intente generar los cambios necesarios que le permitan reapropiarse de su propia voz e intentar controlar a ese engendro voraz que le coarta toda libertad.

\section{Notas}

1. "I began what became a five-year research process, which involved investigation the scarce bibliographical material that exists and interviewing a number of the surviving participants. I did so much research and I interviewed so many people for Guerra en el paraíso that, when people tell me it's a historical novel, I agree, but with the caveat that a typical historical novel reworks a previously existing historical record. In this case, there was no such historical record" (Long, 2006, p. 39).

2. "the established order presents itself as a defense against the violence that would break out if it were not in control, as in social contract theory where political society finds its origin and continued justification in the threat of a state of war" (Bernasconi, 2004, p. 84).

\section{Bibliografía}

Bernasconi, R. (2004). Societies Choose their Dead: a Pheomenology of Systemic Violence. Por M. Staudigl. (Ed.). Fenomenologies of Violence. (81-89). Leiden y Boston: Koninklijke Brill.

Gill, L. (2004). The School of the Americas. Military Training and Political Violence in the Americas. Durham y London: Duke University Press.

Hobbes, T. (s.f.). Leviatán. [pdf]. http://eltalondeaquiles.pucp.edu.pe/recursos/leviatan/ [Consulta 05 de marzo de 2015].

Long, R. (2006). An Interview With Carlos Montemayor. World Literature Today. 80 (2), 38. 
Montemayor, C. (2010). La violencia de Estado en México. Antes y después de 1968. México, D.F.: Random House Mondadori.

Montemayor, C. (2013). Guerra en el paraíso. México, D.F.: Random House Mondadori.

Oikión-Solano, V. (2007). El Estado mexicano frente a los levantamientos armados en Guerrero. El caso del Plan Telaraña. Tzintzun, Revista de Estudios Hispánicos. (45), 65-82.

Pérez-Jiménez, J. C. (2007). Los hijos de Marte y la cultura del miedo. Murcia: Editora Regional de Murcia.

Sontag, S. (2004). Ante el dolor de los demás. (Regarding the pain of Others). Madrid: Punto de lectura.

Vázquez-Martín, E. (1997, 9 de febrero). Entrevista con Carlos Montemayor. El nosotros que todos somos. La Jornada Semanal. http://www.jornada.unam.mx/ [Consulta 16 de marzo de 2015]. 